\title{
El impulso del patrimonio marginado: comprender la evolución del concepto para afrontar nuevos retos
}

Juan Antonio Bermejo das Neves | historiador

URL de la contribución <www.iaph.es/revistaph/index.php/revistaph/article/view/4479>

El concepto de patrimonio está indiscutiblemente ligado a la comunidad al menos desde el siglo XVIII. El patrimonio necesita de la comunidad donde reside (localidad, municipio...) para asegurar su supervivencia y conservación, y la comunidad puede beneficiarse del bien patrimonial a través de la inversión en el mismo. Además, el patrimonio permite la visita turística y otorga un cierto estatus social en el imaginario colectivo al situar el lugar en el mapa mental de las sociedades. Debe ser una relación de sana dependencia.

¿Cómo se forma la idea del patrimonio ligado a su comunidad?, ¿cómo podemos hacer frente a los nuevos retos del patrimonio marginado? Parece claro que el concepto de patrimonio siempre ha existido y que por ello siempre existirá. Esto no resulta del todo cierto: la percepción del patrimonio ha cambiado a lo largo de la historia y si

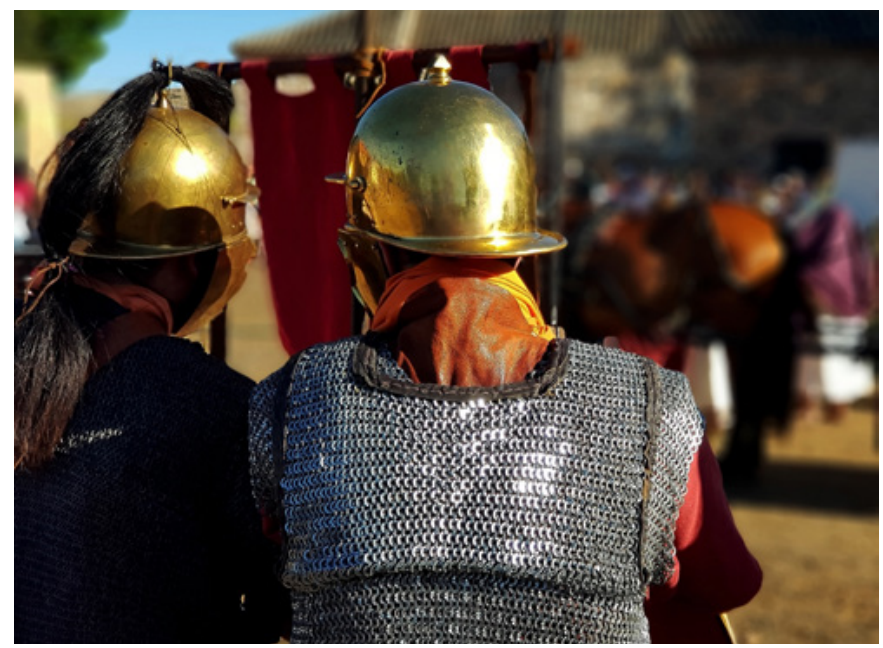

Colaboración entre miembros de la asociación Hispania Romana y voluntarios de Granátula de Calatrava (Ciudad Real) en la celebración de las I Jornadas de ORETVM. Abril, 2019 | fuente Asociación Hispania Romana se encuentra en proceso de cambio -algo que parece intuirse con los nuevos modelos de turismo- los grupos humanos e instituciones vinculados a la cultura y la educación deberíamos de estar preparados para ser impulsores o reguladores del cambio en lugar de tener que manejar el cambio caótico de las modas.

El siglo XVIII marca el cambio histórico principal en la idea patrimonial. La llustración y el Romanticismo convierten el patrimonio en un bien intelectual: ya no se trata de la acumulación de tesorillos en manos de unos pocos personajes ilustres sino que se reflexiona sobre el patrimonio y comienzan las primeras misiones arqueológicas. El bien patrimonial seguirá siendo una barrera para la masa de población pero esta reflexión de los ilustrados servirá, a comienzos del XIX, para ligar el patrimonio con la creación de los Estados modernos. La idea

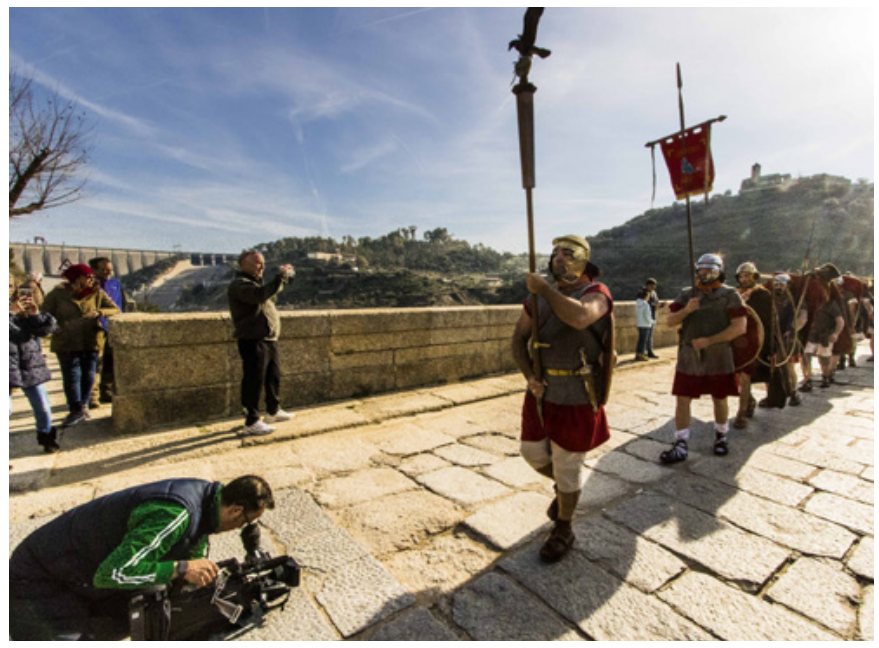

Marcha invernal de la Asociación Hispania Romana por el puente de Alcántara, en la provincia de Cáceres, para reivindicar su deterioro | fuente Asociación Hispania Romana 
a debate ¿Hay patrimonio sin comunidad? Despoblamiento, turistificación y patrimonio cultural

| coordina Jaime Jover Báez

de nación del XIX, tan bien estudiada por el historiador Álvarez Junco, necesita de la vinculación al patrimonio, pues será el signo físico de la historia nacional y a lo largo de ese siglo se buscará implicar a las nuevas clases sociales en la transmisión del patrimonio histórico de la nación. Este proceso de creación del imaginario colectivo vendrá dado por personajes como Goethe, Mommsen o Goya. Para comprender el éxito de este proceso basta con pensar en países y asociar un monumento a cada uno para comprender hasta qué punto tenemos interiorizado el patrimonio como elemento vinculado a la nación.

El siguiente paso en el cambio del concepto de patrimonio será su asociación con el turismo a partir de mediados del siglo XX. El turismo de masas, donde ya participan amplias capas de la sociedad, se convertirá en su principal impulsor. La sociedad se desplazará a las comunidades "propietarias" (recordemos la asociación del bien patrimonial a su región) y esto traerá toda una industria turística desde el origen a la comunidad de destino, ligando así la comunidad con el patrimonio. Sin embargo hoy es causa de titulares la masificación del turismo, aunque esto ya se venía advirtiendo desde hace tiempo entre los profesionales del turismo bajo el concepto del turismo de foto o del check, es decir: la necesidad de los visitantes de elaborar una lista de "qué ver", hacer la foto y marcar el check en la lista. Este nuevo turismo no solo empobrece la experiencia cultural convirtiendo el patrimonio en un objetivo sin entrar a valorarlo, sino que también supone seleccionar un tipo de patrimonio que acaba masificado (Barcelona, Venecia) y marginar todo el patrimonio que no entra en la lista del check.

Este patrimonio marginado supone un peligro para la comunidad y viceversa. La relación de dependencia mutua de la que hablábamos al comienzo se rompe: el bien patrimonial no produce industria turística y la comunidad no invierte en su mantenimiento y puesta en valor y esto conduce a procesos de migración a otros pueblos o ciudades con mayor capacidad, con el consecuente deterioro del patrimonio de la comunidad y la desaparición del sentimiento de pertenencia o propiedad imagi-

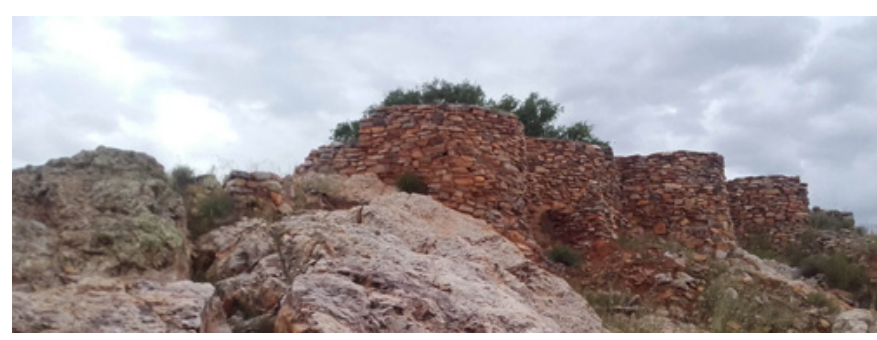

Vista de los baluartes defensivos del Oppida de la Encantada, Edad del Bronce (Granátula de Calatrava; Ciudad Real)

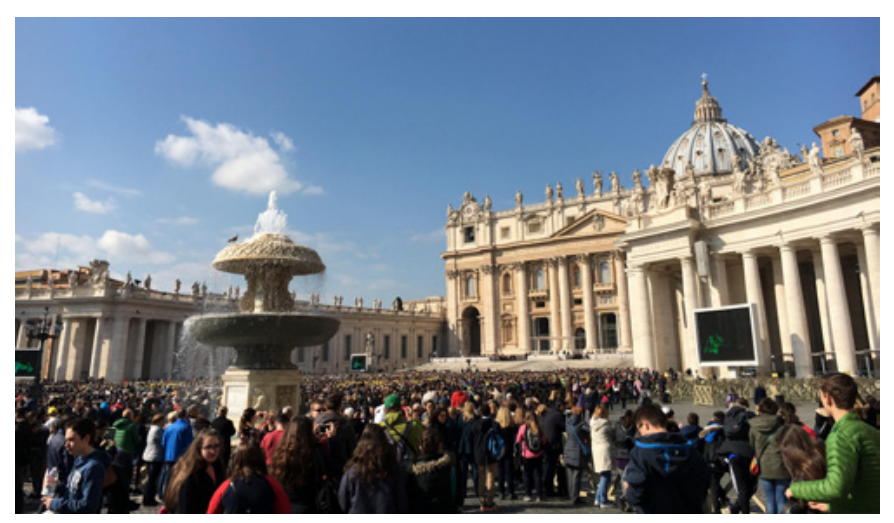

Masificación en puntos turísticos marcados en la "agenda del turista". Plaza de San Pedro en el Vaticano, 2016 | fotos Juan Antonio Bermejo

nada que tan difícilmente se había construido durante el siglo XIX.

¿Contamos con proyectos que pueden ayudar al patrimonio marginado y a los procesos de despoblamiento asociados a la ausencia de industria turística en poblaciones sin otros recursos que fomenten una industria paralela? En este proceso de ser los impulsores o reguladores del cambio turístico me interesa llamar la atención hacia proyectos culturales que buscan un equilibro entre el fomento de la industria turística y el impulso responsable de un patrimonio local lejano de la idea del check.

Uno de los ejemplos más recientes merecedores de atención es el de Granátula de Calatrava (Ciudad Real), localidad con un ingente patrimonio que parte de la Edad del Bronce, con importancia destacada en época púnica, romana y visigoda, numerosos edificios históricos desde 
finales del medievo, cuna del general Espartero y un importante patrimonio natural dentro de la región volcánica del campo de Calatrava. El despoblamiento por la emigración, la ausencia de industria paralela y la falta de inversión en patrimonio, amenazaron hace un par de años la pervivencia del colegio público local pero una iniciativa popular nacida en el colegio intenta revertir esta situación fomentando un turismo sostenible basado en unas jornadas de promoción del pasado ibero-romano.

El peligro de este tipo de iniciativas viene dado por la posible deriva hacia una fiesta popular que tan solo atraiga a la comunidad inmediata. Para evitar esto es necesario el apoyo de organizaciones vinculadas al patrimonio. En este caso se contó con la asesoría de la Asociación Hispania Romana, con una trayectoria de 15 años y presencia en lugares destacados como Itálica o Lucentum en calidad de recreadores históricos y que recientemente también colaboró con las asociaciones locales de Alcántara (Cáceres) para visibilizar el deterioro del puente romano.

Es necesario entender el patrimonio como algo cambiante para el imaginario colectivo para así poder afrontar los nuevos retos del XXI. Ante el peligro del patrimonio marginado por los nuevos modelos turísticos, es necesaria la participación de la comunidad junto con el apoyo de instituciones vinculadas al patrimonio de cara a fomentar un turismo cultural responsable, capaz de reactivar la industria turística local.

\section{BIBLIOGRAFÍA}

- COLORIDA reclamación de los vecinos de Alcántara en defensa de su puente romano. Canal Extremadura [en línea], 16 de febrero de 2019 <http://www.canalextremadura.es/portada/ actualidad/colorida-reclamacion-de-los-vecinos-de-alcantaraen-defensa-de-su-puente-romano> [Consulta: 01/07/2019]

- Álvarez JunCO, J. (2016) Dioses útiles. Nacionales y nacionalismos. Barcelona: Editorial Galaxia Gutenberg, 2016

- BERMEJO DAS NEVES, J. A. (2015) Tablilla de Cera. Divulgación, enseñanza, patrimonio [en línea] <http://www. tablilladecera.com> [Consulta: 01/07/2019]
- GRANÁTULA de Calatrava rememoró su pasado ibero y romano con las primeras Jornadas Nacionales "Iberom". Diario digital ciudadano [en línea], 3 de junio de $2019<$ https:// www.miciudadreal.es/2019/06/03/granatula-de-calatravarememoro-su-pasado-ibero-y-romano-con-las-primerasjornadas-nacionales-iberom/> [Consulta: 01/07/2019]

- LLULL, J. (2005) Evolución del concepto y de la significación social del patrimonio cultural. Arte, Individuo y Sociedad, n. ${ }^{0}$ 17,2005 , pp. $175-204$ 